\title{
Relationships between Metabolic Syndrome Component and Depression, Stress
}

\author{
Moon-Jung Shim ${ }^{1}$ and Yun-Jung Kang ${ }^{2}$ \\ ${ }^{1}$ Department of Clinical Laboratory Science, Ansan University, Ansan 426-701, Korea \\ ${ }^{2}$ Department of Health Science, Dankook University Graduate School, Cheonan 330-714, Korea
}

\begin{abstract}
The purpose of this study is to provide an academic basis regarding the necessity of managing depression and stress among metabolic syndrome patients by understanding 5 components of metabolic syndrome, perceived stress, and degree of depression, and by investigating their association using the national nutrition survey reference. This study was conducted by using mental health surveys and health screening test data of the 5th (2010 2012) primitive data of the national health and nutrition survey. A total of 19,599 respondents over 19 years of age were selected for the final analysis. The level of depression and stress was set as the dependent variable to identify its connection with 5 components of the metabolic syndrome. For the stress recognition, none of the metabolic syndrome components showed a significant correlation. For experiencing the depression symptom, the fasting glucose among the factors showed a significant correlation ( $p$ $<0.05)$ among the metabolic syndrome factors. When it falls within the criteria of fasting glucose of metabolic syndrome, it has a great probability of falling under the group who experienced greater depression symptoms. As a result of the analysis by controlling cardiovascular and cerebrovascular disease which is tightly related with metabolic syndrome and depression, this study observed that glucose out of 5 metabolic syndrome components is related with depression.
\end{abstract}

Keywords: Metabolic syndrome component, Stress, Depression

This is an Open Access article distributed under the terms of the Creative Commons Attribution Non-Commercial License (http://creativecommons.org/licenses/by-nc/3.0) which permits unrestricted non-commercial use, distribution, and reproduction in any medium, provided the original work is properly cited.

Copyright (C) 2014 The Korean Society for Clinical Laboratory Science. All rights reserved.
Corresponding author: Yun-Jung Kang Department of Health Science,

Dankook University Graduate School,

Cheonan 330-714, Korea

Tel: 82-41-683-2657

E-mail: yun_jung83@hanmail.net

Received: June 7, 2014

Revised: June 15, 2014

Accepted: June 15, 2014

\section{서 론}

대사증후군은 과거에는 $\mathrm{X}$ 증후군, 혹은 인슐린저항성 증후군으 로 혼용되어 불리던 질환으로 이러한 질환들과 밀접한 연관이 있는 복부비만, 고중성지방혈증, 저HDL콜레스테롤혈증, 고혈압 및 고 혈당 5 개의 위험 인자 가운데 3 가지 이상이 집중되어 나타나는 증 상을 대사증후군으로 분류한다. 대사증후군은 복부비만, 인슐린저 항 등으로 발생하는 질병이면서 당뇨병, 고혈압, 만성 신장병, 심뇌 혈관질환 및 전체 사망률 증가의 원인이 되는 위험인자로 생각되며, 혈관 내피세포 기능장애, 체내 염증 증가와 이소성 지방 축적을 일 으켜 대사이상 및 심뇌혈관 질환의 위험인자로 알려져 있다. 대사 증후군 환자들은 대사증후군의 각각 다른 진단기준에 상관없이 심 뇌혈관질환 발생 가능성이 2배 이상 높았다(Hadaegh 등, 2012). Schmidt와 Bergstrom (2012)의 연구에 따르면 대사증후군 환자 를 평균 13년 추적한 결과, 심근경색, 뇌졸중 등을 포함하는 심뇌혈
관질환 발생 위험이 약 2 배 가량 높음을 보였다. 대사증후군이 임상 적으로 중요한 이유는 최종 합병증으로 죽상경화증에 의한 심혈관 질환, 뇌혈관 질환 및 말초혈관 질환이 발생하기 때문이다. 즉 고인 슐린혈증, 고혈압, 이상지혈증 등은 그 자체가 질병이기도 하지만 심혈관 및 뇌혈관 질환의 위험인자로 작용하여, 대사증후군에서는 이들 위험인자가 죽상경화증을 유발하고 진행을 촉진하는 것으로 알려져 있다(김 등, 2005). 가장 최근에 발표된 미국 국민건강영양 조사자료에 의하면 대사증후군과 뇌졸중은 깊은 상관 관계를 보인 다(Ninomiya 등, 2004). 단면적 연구에서도 대사증후군은 뇌졸중 환자에서 높은 유병률을 보인다. 네덜란드 연구에서, 대사증후군은 새로 진단받은 뇌졸중 환자의 43\%에서 나타났다(Olijhoek 등, 2004). 국내의 한 대학병원에 입원한 허혈성뇌졸중 환자를 대상으 로 한 연구에서도 남자는 $36 \%$, 여자는 $49 \%$ 가 대사증후군을 가지고 있는 것으로 나타났다(조 등, 2003). 뇌졸중 환자는 거의 5명 중 한 명꼴로 우울증을 겪는다는 Husseini 등(2012)의 연구결과가 있다. 
뇌졸중의 대부분을 차지하는 허혈성 뇌졸중환자 1 천 450 명과 “미 니" 뇌졸중인 일과성 허혈발작을 겪은 397 명을 지켜본 결과 뇌졸중 환자는 입원 3 개월 후 $18 \%$, 일과성 허혈발작 환자는 $14 \%$ 가 우울증 이 나타났다. 입원 12 개월 후 우울증 발생률은 뇌졸중 환자가 $16.4 \%, \mathrm{TIA}$ 환자가 $13 \%$ 로 나타났다. 뇌졸중과 일과성 허혈발작 환 자의 우울증 발생률이 거의 비슷한 것은 뇌 손상이 우울증 발생에 직접적인 영향을 미치기 때문임을 시사하는 것으로 해석했다. 다른 선행된 연구결과에서도 고혈압, 당뇨 그리고 심장질환 등 혈관성 질환이 우울증을 유발한다는 주장도 보고되고 있어 심뇌혈관과 우 울은 깊은 관련성을 보인다(Alexopoulus 등, 1997). 그에 따라 심 뇌혈관계 질환의 위험인자이며, 전향적인자이고 혈관 내피세포 기 능장애 단계인 대사증후군과 우울, 스트레스의 관련성을 배제 할 수 없다. 국내 우울증과 대사증후군 관련된 윤 등(2005)의 연구결 과에서 우울증상과 대사증후군 5가지 요소(허리둘레, 고혈압, 중성 지방, 당뇨, 고밀도-콜레스테롤)간 연관성 분석에서는 혈당 상승과 복부 비만이 통계적으로 유의성을 보였다. 그러나 우울증 평가에 있어 표준화된 진단적 접근을 하지 못한 점과 연구 대상이 비교적 건강관리에 관심이 높은 검진 수진자였기 때문에 지역 사회인구를 대표한다고 보기 어렵다는 제한점이 있다. 인과론적 관계에 대해서 는 추가적인 연구가 필요한 상황이고 두 질환 간 상호적인 관계가 존재할 가능성도 존재한다. 또한 대사증후군 자체가 심뇌혈관질환 의 위험인자라기보다는 대사증후군을 구성하는 각각의 진단 요소 가 심뇌혈관질환의 위험성을 증가시켰을 가능성이 높다(Horwich 와 Fonarow, 2010). 이러한 점을 고려하여 본 연구는 우울, 스트레 스와 관련 깊은 심뇌혈관질환을 통제하며, 대사증후군 5 가지 요소 와 우울, 스트레스의 관련성을 파악하고자 한다. 이에 본 연구는 국 민건강영양조사자료를 활용하여 대사증후군 5가지 요소와 지각된 스트레스, 우울 정도를 파악하고 이들의 상관관계를 규명하여 대사 증후군 환자들의 우울과 스트레스 관리의 필요성에 대한 학문적 근 거를 제공하고자 한다.

\section{재료 및 방법}

\section{1. 연구대상}

이 연구는 '국민건강영양조사 제5기(2010 2012) 원시자료'의 정신건강설문조사와 건강검진자료를 활용하여 수행하였다. 이는 복합표본설계 자료로서, 모집단인 대한민국 전체 인구의 지역별, 연령대별 인구비율 특성을 잘 반영하도록 3단계 층화집락표본추출 방법을 적용한 것이다. 1, 2, 3차년도(2010 2012)자료를 가중치 비율 1:1:1을 적용하여 통합하였고, 전체 25,534 건 중 만 19 세 이 상인 응답자에 해당하는 19,599 건을 최종 분석 대상으로 하였다.

\section{2. 연구방법}

1) 대사증후군 5 가지 요소의 정의

최근 가정의학회에서 간행한 '대한민국 성인에서 대사증후군의 예방 및 치료' 임상진료 지침을 근거하여 대사증후군 5가지 요소를 정의하였다.

(1) 복부비만: 남자 허리둘레 $\geq 90 \mathrm{~cm}$, 여자 허리둘레 $\geq 85 \mathrm{~cm}$ (대한비만학회 진단기준에 근거) (Korean society for the study of obesity, 2008)

(2) 고중성지방혈증: $\geq 150 \mathrm{mg} / \mathrm{dL}(1.695 \mathrm{mmol} / \mathrm{L})$

(3) 저HDL-콜레스테롤혈증: 남자 < $40 \mathrm{mg} / \mathrm{dL}(1.036 \mathrm{mmol} / \mathrm{L})$, 여자 $<50 \mathrm{mg} / \mathrm{dL}(1.295 \mathrm{mmol} / \mathrm{L})$

(4) 고혈압: $\geq 130 / 85 \mathrm{mmHg}$ 이거나 항고혈압제를 복용하고 있 는 경우

(5) 고혈당: $\geq 100 \mathrm{mg} / \mathrm{dL}$ ( $\geq 6.1 \mathrm{mmol} / \mathrm{L}$ )이거나 인슐린 혹은 경구혈당강하제를 사용하고 있는 경우

\section{2) 우울, 스트레스 평가}

건강 설문에서 정신건강상태를 알아보기 위한 스트레스 인지정 도는 평소 일상생활 중에 스트레스를 많이 느끼는 분율로 '적게 느 낀다', '많이 느낀다'로 구분하였다. 우울감은 최근 1년 동안 연속 적으로 2주 이상 일상생활에 지장이 있을 정도로 슬프거나 절망감 을 느낀 분율로 예, 아니오로 구분하였다.

\section{3. 자료의 분석}

수집한 데이터는 SPSS 22 를 사용하였으며, 일반적 특성에 따른 빈도분석 및 정신건강, 대사증후군과의 관련성에 대한 카이제곱 분 석, 대사증후군 5 가지 요소와 정신건강에 대한 영향력을 파악하기 위한 로지스틱 회귀분석을 실시하였다.

\section{결 과}

\section{1. 조사대상자의 일반적 특성}

연구의 분석에 활용된 대상자들의 특성 중 연령대는 19 44세 가 전체의 $50.8 \%$ 로 가장 많았고, $45 \sim 64$ 세(34.7\%), 65세 이상 (14.5\%)었으며, 이 중 남성은 7,902명(49.4\%) 여성은 10,669 명 (50.6\%)였다(Table 1).

\section{2. 일반적 특성과 스트레스 인지여부 관계 카이제곱 분석}

일반적 특성과 스트레스 인지여부의 관계성을 확인하기 위해 카 이제곱 분석을 실시하였다. 모든 응답에서 스트레스를 낮게 인지한 집단이 높게 인지한 집단보다 높은 비율을 차지했으나, 응답 값 별 
70 Moon-Jung Shim and Yun-Jung Kang. Metabolic Syndrome Component and Depression, Stress

Table 1. General Characteristics of the Study subjects

\begin{tabular}{|c|c|c|c|c|c|}
\hline Characteristic & & Estimate & Standard error & Unweighted count & Estimate (\%) \\
\hline \multirow[t]{3}{*}{ Gender } & Male & 19241184 & 361011 & 7902 & 49.40 \\
\hline & Female & 19742463 & 353664 & 10669 & 50.60 \\
\hline & Total & 38983647 & 653000 & 18571 & 100.00 \\
\hline \multirow[t]{4}{*}{ Age (years) } & $19 \sim 44$ & 19816142 & 473222 & 7284 & 50.80 \\
\hline & $45 \sim 64$ & 13533332 & 291283 & 6730 & 34.70 \\
\hline & $\geq 65$ & 5634173 & 159249 & 4557 & 14.50 \\
\hline & Total & 38983647 & 653000 & 18571 & 100.00 \\
\hline \multirow[t]{5}{*}{ Educational level } & $\leq$ Elementary & 7047000 & 209330 & 4606 & 18.80 \\
\hline & Middle & 3784847 & 121018 & 1948 & 10.10 \\
\hline & High & 14547445 & 377816 & 5939 & 38.90 \\
\hline & $\geq$ College & 12024932 & 328527 & 5367 & 32.10 \\
\hline & Total & 37404224 & 640804 & 17860 & 100.00 \\
\hline \multirow[t]{6}{*}{ Alcohol consumption } & Non & 8595760 & 198279 & 5098 & 23.10 \\
\hline & $\leq 1$ time/month & 10817050 & 252566 & 5201 & 29.00 \\
\hline & $2 \sim 4 /$ month & 9105346 & 236540 & 3795 & 24.40 \\
\hline & $2 \sim 3 /$ week & 5965889 & 176558 & 2451 & 16.00 \\
\hline & 4+/week & 2796227 & 115755 & 1252 & 7.50 \\
\hline & Total & 37280272 & 639698 & 17797 & 100.00 \\
\hline \multirow[t]{4}{*}{ Smoking } & Non & 20108509 & 371298 & 10566 & 53.70 \\
\hline & Former & 7397029 & 180244 & 3632 & 19.80 \\
\hline & Current & 9934722 & 255584 & 3673 & 26.50 \\
\hline & Total & 37440260 & 640519 & 17871 & 100.00 \\
\hline
\end{tabular}

Missing cases are included.

Table 2. The Stress awareness Level according to Subjects' Characteristics

\begin{tabular}{|c|c|c|c|c|c|c|}
\hline \multirow{3}{*}{ Variables } & \multicolumn{4}{|c|}{ Stress awareness } & \multirow{3}{*}{$\chi^{2}$} & \multirow{3}{*}{$p$} \\
\hline & \multicolumn{2}{|c|}{ Low } & \multicolumn{2}{|c|}{ High } & & \\
\hline & Estimate (\%) & Standard error (\%) & Estimate (\%) & Standard error (\%) & & \\
\hline Gender & & & & & 81.469 & $<0.01$ \\
\hline Male & 75.35 & 0.66 & 24.65 & 0.66 & & \\
\hline Female & 69.31 & 0.60 & 30.69 & 0.60 & & \\
\hline Age (years) & & & & & 142.991 & $<0.01$ \\
\hline $19 \sim 44$ & 68.43 & 0.67 & 31.57 & 0.67 & & \\
\hline $45 \sim 64$ & 75.72 & 0.64 & 24.28 & 0.64 & & \\
\hline$\geq 65$ & 77.86 & 0.87 & 22.14 & 0.87 & & \\
\hline Marital status & & & & & 39.228 & $<0.01$ \\
\hline With spouse & 73.90 & 0.51 & 26.10 & 0.51 & & \\
\hline Without spouse & 69.07 & 0.89 & 30.93 & 0.89 & & \\
\hline Educational level & & & & & 61.655 & $<0.01$ \\
\hline$\leq$ Elementary & 73.72 & 0.77 & 26.28 & 0.77 & & \\
\hline Middle & 77.84 & 1.28 & 22.16 & 1.28 & & \\
\hline High & 72.81 & 0.72 & 27.19 & 0.72 & & \\
\hline$\geq$ College & 69.07 & 0.78 & 30.93 & 0.78 & & \\
\hline Alcohol consumption & & & & & 27.372 & $<0.01$ \\
\hline Non & 74.89 & 0.75 & 25.11 & 0.75 & & \\
\hline$\leq 1$ time/month & 72.58 & 0.79 & 27.42 & 0.79 & & \\
\hline $2 \sim 4 /$ month & 71.83 & 0.94 & 28.17 & 0.94 & & \\
\hline $2 \sim 3 /$ week & 70.25 & 1.16 & 29.75 & 1.16 & & \\
\hline 4+/week & 69.07 & 1.76 & 30.93 & 1.76 & & \\
\hline Smoking & 68.34 & 2.09 & 31.66 & 2.09 & 76.884 & $<0.01$ \\
\hline Non & 73.04 & 0.55 & 26.96 & 0.55 & & \\
\hline Former & 76.23 & 0.89 & 23.77 & 0.89 & & \\
\hline Current & 67.84 & 1.06 & 32.16 & 1.06 & & \\
\hline
\end{tabular}

Missing cases are included.

$p<0.05, p<0.001$. 
로 그 구성 비율이 달랐다. 성별의 경우, 여성이 남성보다 스트레스 를 높게 인지한 집단에 속한 비율이 높았다 $(p<0.01)$. 연령대는 낮 을수록 스트레스가 높다고 응답한 비율이 높았다 $(p<0.01)$. 음주 빈도는 높을수록 스트레스를 높게 인지한 집단에 속한 비율이 높았 다 $(p<0.01)$. 흡연은 현재 흡연자가 가장 스트레스가 높다고 응답 하였다 $(p<0.01)$ (Table 2$)$.

\section{3. 일반적 특성과 우울증상 경험여부 관계 카이제곱 분석}

일반적 특성과 우울증상 경험여부의 관계성을 확인하기 위해 카 이제곱 분석을 실시하였다. 여성이 남성보다 우울증상을 많이 경험 한 집단에 속한 비율이 높았다 $(p<0.01)$. 연령대는 높을수록 우울 증상을 많이 경험한 집단에 속한 비율이 높았다 $(p<0.01)$. 소득수 준은 낮을수록 우울증상을 많이 경험한 집단에 속한 비율이 높았다 $(p<0.01)$. 교육수준은 낮을수록 우울증상을 많이 경험한 집단에 속한 비율이 높았다 $(p<0.01)$. 흡연에 따라서는 전혀 흡연한 적 없 는 경우, 현재 흡연하는 경우, 이전에 흡연하였으나 지금은 하지 않 는 경우 순으로 우울증상을 많이 경험한 집단에 속한 비율이 높았
다 $(p<0.01)$ (Table 3).

\section{4. 일반적 특성과 대사증후군 여부 관계 카이제곱 분석}

일반적 특성과 대사증후군 여부의 관계성을 확인하기 위해 카이 제곱 분석을 실시하였다. 연령대가 높을수록 대사증후군에 해당되 는 비율이 높았다 $(p<0.01)$. 교육수준은 낮을수록 대사증후군에 해당되는 비율이 높았다 $(p<0.01)$. 음주 빈도는 매주 4 회 이상, 전 혀 하지 않는 경우, 매주 2 3회, 매월 2 4회, 매월 1회 이상 순으 로 대사증후군에 해당되는 비율이 높았다 $(p<0.01)$. 운동 빈도는 1 주일 기준으로 매일, 전혀 안함, 3 4일, 1 2일, 5 6일 순으로 대 사증후군에 해당되는 비율이 높았다 $(p<0.05)$. 뇌졸중 여부와 심 혈관계 질환 여부는 대사증후군과 유의한 관련성을 보였다. 뇌졸중 에 해당하면 대사증후군에도 해당하는 경우가 유의하게 많았다 $(p$ $<0.01)$. 이와 유사하게, 심근경색증 및 협심증에 해당하면 대사증 후군에도 해당하는 경우가 유의하게 많았다 $(p<0.01)$ (Table 4).

Table 3. The Depression recognition according to Subjects' Characteristics

\begin{tabular}{|c|c|c|c|c|c|c|}
\hline \multirow{3}{*}{ Variables } & \multicolumn{4}{|c|}{ Depression recognition } & \multirow{3}{*}{$\chi^{2}$} & \multirow{3}{*}{$p$} \\
\hline & \multicolumn{2}{|c|}{ Low } & \multicolumn{2}{|c|}{ High } & & \\
\hline & Estimate (\%) & Standard error (\%) & Estimate (\%) & Standard error (\%) & & \\
\hline Gender & & & & & 229.587 & $<0.01$ \\
\hline Male & 90.86 & 0.41 & 9.14 & 0.41 & & \\
\hline Female & 83.24 & 0.47 & 16.76 & 0.47 & & \\
\hline Age (years) & & & & & 94.784 & $<0.01$ \\
\hline $19 \sim 44$ & 89.37 & 0.44 & 10.63 & 0.44 & & \\
\hline $45 \sim 64$ & 84.74 & 0.53 & 15.26 & 0.53 & & \\
\hline$\geq 65$ & 83.89 & 0.70 & 16.11 & 0.70 & & \\
\hline Marital status & & & & & 50.892 & $<0.01$ \\
\hline With spouse & 87.86 & 0.37 & 12.14 & 0.37 & & \\
\hline Without spouse & 83.68 & 0.69 & 16.32 & 0.69 & & \\
\hline Educational level & & & & & 208.221 & $<0.01$ \\
\hline$\leq$ Elementary & 80.77 & 0.72 & 19.23 & 0.72 & & \\
\hline Middle & 83.87 & 1.01 & 16.13 & 1.01 & & \\
\hline High & 87.60 & 0.55 & 12.40 & 0.55 & & \\
\hline$\geq$ College & 90.86 & 0.46 & 9.14 & 0.46 & & \\
\hline Alcohol consumption & & & & & 42.625 & $<0.01$ \\
\hline Non & 84.43 & 0.62 & 15.57 & 0.62 & & \\
\hline$\leq 1$ time/month & 87.10 & 0.57 & 12.90 & 0.57 & & \\
\hline $2 \sim 4 /$ month & 88.65 & 0.63 & 11.35 & 0.63 & & \\
\hline $2 \sim 3 /$ week & 88.60 & 0.79 & 11.40 & 0.79 & & \\
\hline 4+/week & 85.75 & 1.30 & 14.25 & 1.30 & & \\
\hline Smoking & & & & & 20.338 & $<0.01$ \\
\hline Non & 86.18 & 0.42 & 13.82 & 0.42 & & \\
\hline Former & 89.17 & 0.61 & 10.83 & 0.61 & & \\
\hline Current & 87.01 & 0.66 & 12.99 & 0.66 & & \\
\hline
\end{tabular}

Missing cases are included. $p<0.05, p<0.001$. 
72 Moon-Jung Shim and Yun-Jung Kang. Metabolic Syndrome Component and Depression, Stress

Table 4. The Metabolic Syndrome according to Subjects' Characteristics

\begin{tabular}{|c|c|c|c|c|c|c|}
\hline \multirow{3}{*}{ Variables } & \multicolumn{4}{|c|}{ Metabolic syndrome } & \multirow{3}{*}{$\chi^{2}$} & \multirow{3}{*}{$p$} \\
\hline & \multicolumn{2}{|c|}{ Non } & \multicolumn{2}{|c|}{ Yes } & & \\
\hline & Estimate (\%) & Standard Error (\%) & Estimate (\%) & Standard Error (\%) & & \\
\hline Gender & & & & & 44.369 & $<0.01$ \\
\hline Male & 73.32 & 0.80 & 26.68 & 0.80 & & \\
\hline Female & 78.42 & 0.71 & 21.58 & 0.71 & & \\
\hline Age (years) & & & & & 769.248 & $<0.01$ \\
\hline $19 \sim 44$ & 86.45 & 0.65 & 13.55 & 0.65 & & \\
\hline $45 \sim 64$ & 67.92 & 0.89 & 32.08 & 0.89 & & \\
\hline$\geq 65$ & 60.45 & 1.24 & 39.55 & 1.24 & & \\
\hline Marital status & & & & & 107.673 & $<0.01$ \\
\hline With spouse & 73.29 & 0.67 & 26.71 & 0.67 & & \\
\hline Without spouse & 81.86 & 0.87 & 18.14 & 0.87 & & \\
\hline Educational level & & & & & 480.917 & $<0.01$ \\
\hline$\leq$ Elementary & 60.91 & 1.20 & 39.09 & 1.20 & & \\
\hline Middle & 66.56 & 1.63 & 33.44 & 1.63 & & \\
\hline High & 80.21 & 0.87 & 19.79 & 0.87 & & \\
\hline$\geq$ College & 82.47 & 0.84 & 17.53 & 0.84 & & \\
\hline Alcohol consumption & & & & & 163.643 & $<0.01$ \\
\hline Non & 71.17 & 1.01 & 28.83 & 1.01 & & \\
\hline$\leq 1$ time/month & 81.41 & 0.89 & 18.59 & 0.89 & & \\
\hline $2 \sim 4 /$ month & 78.67 & 1.07 & 21.33 & 1.07 & & \\
\hline $2 \sim 3 /$ week & 73.51 & 1.27 & 26.49 & 1.27 & & \\
\hline $4+/$ week & 65.70 & 2.19 & 34.30 & 2.19 & & \\
\hline Smoking & & & & & 70.932 & $<0.01$ \\
\hline Non & 78.86 & 0.71 & 21.14 & 0.71 & & \\
\hline Former & 71.57 & 1.13 & 28.43 & 1.13 & & \\
\hline Current & 72.96 & 1.11 & 27.04 & 1.11 & & \\
\hline Stroke & & & & & 39.844 & $<0.01$ \\
\hline Non & 76.10 & 0.61 & 23.90 & 0.61 & & \\
\hline Yes & 56.00 & 3.66 & 44.00 & 3.66 & & \\
\hline Myocardial infarction/Angina pectoris & & & & & 29.624 & $<0.01$ \\
\hline Non & 76.13 & 0.61 & 23.87 & 0.61 & & \\
\hline Yes & 62.09 & 3.02 & 37.91 & 3.02 & & \\
\hline
\end{tabular}

Missing cases are included.

$p<0.05, p<0.001$.

Table 5. The Effects of Metabolic Syndrome on the Mental Health

\begin{tabular}{|c|c|c|c|}
\hline Dependent Variable (High) & Criterion (Yes) & Odds ratio & $p$ \\
\hline \multirow[t]{5}{*}{ Stress awareness } & Waist circumference $(\mathrm{cm})$ & 1.126 & n.s. \\
\hline & Triglycerides (mg/dL) & 1.015 & n.s. \\
\hline & HDL-Cholesterol (mg/dL) & 0.940 & n.s. \\
\hline & blood pressure $(\mathrm{mm} \mathrm{Hg})$ & 1.116 & n.s. \\
\hline & Fasting Glucose (mg/dL) & 1.002 & n.s. \\
\hline \multirow[t]{5}{*}{ Depression recognition } & Waist circumference $(\mathrm{cm})$ & 0.941 & n.s. \\
\hline & Triglycerides (mg/dL) & 0.985 & n.s. \\
\hline & HDL-Cholesterol (mg/dL) & 0.930 & n.s. \\
\hline & Blood pressure (mm Hg) & 0.960 & n.s. \\
\hline & Fasting Glucose (mg/dL) & 1.222 & $<0.05$ \\
\hline
\end{tabular}

Missing cases are included. Results of logistic regression. Reference Category=Low, Non; Control Variables=Gender, Age(years), Marital status, Income, Educational level, Economic activity, Alcohol consumption, Excercise, Smoking, Stroke, Myocardial infarction/Angina pectoris. 


\section{5. 대사증후군이 우울, 스트레스에 미치는 영향}

스트레스 인지여부와 우울증상 경험여부 각각에 대한 대사증후 군 요소의 영향을 알아보기 위해 로지스틱 회귀분석을 실시하였다. 일반적 특성과 뇌졸중 유병여부, 심근경색/협심증 유병여부를 포 함한 전체 모형은 유의한 설명력을 가지고 있는 것으로 나타났다 (Wald ${ }^{2}=306.740, p<0.01$, Wald ${ }^{2}=337.053, p<0.01$ ). 스트 레스 인지여부에 대해서는 대사증후군 요소 중 어느 것도 유의한 연관성을 보이지 않았다. 우울증상 경험여부에 대해서는 대사증후 군 요소 중 공복혈당이 유의한 연관성을 보였다 $(p<0.05)$. 대사증 후군의 공복혈당 기준에 해당할 경우 우울증상을 많이 경험한 집단 에 속할 확률은 1.222배 높아졌다(Table 5).

\section{고 찰}

본 연구에서는 국민건강영양조사 자료를 활용하여 국내 성인을 대상으로 대사증후군 요소와 우울, 스트레스의 연관성을 평가하고 자 하였다. 연구대상자의 일반적 특성에 대해 살펴본 결과 배우자 와 동거하고 있는 경우가 미혼, 이혼, 사별, 별거 등으로 배우자와 동거하고 있지 않은 경우보다 대사증후군에 해당되는 비율이 높았 으며 $(p<0.01)$ 교육수준이 낮을수록 대사증후군에 해당되는 비율 이 높았다(Table 4). 이는 2007 2011년 국민건강영양조사 결과 를 바탕으로 환경적 요인이 대사증후군에 미치는 영향을 조사한 권 (2013)의 연구결과와 일치한다. 성별에 따른 우울 경험율을 보면, 여성이 남성보다 우울증상을 많이 경험한 집단에 속한 비율이 높았 다 $(p<0.01)$ (Table 3). 이는 선행연구에서 여자가 남자보다 우울 유병률이 높다는 송 등(2008)의 연구결과와 부합한다. 교육수준이 낮을수록 우울증상을 많이 경험한 집단에 속한 비율이 높았으며, 선행연구에서도 동일한 결과가 보고되었다(Park 등, 2009). 이는 교육수준이 대사증후군과 정신건강에 간접적으로 영향을 주고 있 다고 볼 수 있겠다. 뇌졸중 여부와 심혈관계 질환 여부는 대사증후 군과 유의한 관련성을 보였다. 이는 심뇌혈관과 대사증후군 관련 선행연구들과 일치한다(Hadaegh 등, 2012). 이러한 영향을 고려 하여 로지스틱 회귀분석 시 성별, 결혼상태, 교육수준, 뇌졸중 여부 와 심혈관계 질환 여부 등을 통제변수로 공변량에 투입하여 분석하 였다. 그 결과 스트레스 인지여부에 대해서는 대사증후군 요소 중 어느 것도 유의한 연관성을 보이지 않았으며 우울증상 경험 여부에 대해서는 공복혈당이 유의한 연관성을 보였다(Table 5). 이는 노인 을 대상으로 한 최 등(2010)의 연구결과와 여성을 대상으로 한 윤 등(2005)의 연구결과 에서 당뇨병을 진단 받은 경우 우울인지에 유 의한 영향을 미치는 결과와 부합하다. 대사증후군과 우울증 두 질 환이 상호적인 관계를 가졌을 가능성이 있다. 혈관성 우울증 가설 (vascular depression hypothesis)은 고혈압, 당뇨, 심장질환 그리 고 동맥경화 등 혈관성 질환들이 뇌피질하 영역에 소혈관 질환 발 생을 야기하고 이것이 신경생물학적 기능에 장애를 일으켜 우울증 상을 발생 시킨다는 개념이다(Alexopoulus 등, 1997). 실제로 뇌 자기공명영상 연구에서 심혈관계 질환, 뇌 소혈관질환, 그리고 Warren 등(2003)의 연구에서 우울증간 연관성이 보고되고 있는데 최근에는 대사증후군이 뇌 소혈관질환 발생에 독립적인 위험인자 임이 권 등(2006)에 의해 보고되었고, 이것은 대사증후군이 혈관성 우울증 가설에 근거하여 우울증을 발생 및 악화 시킬 수 있다는 추 론을 가능케 한다. 또 다른 추론으로는 당뇨병은 오랜 기간 관리해 야 하는 질환으로 경제적, 심리적 부담감이 클 수 밖에 없다. 그로 인 해 오는 스트레스는 우울을 유발하는 외적자극으로 작용하기도 한 다(Heuser, 2002). 또한 스트레스와 우울은 대사증후군환자의 건 강생활양식을 악화시켜 대사증후군의 위험을 증가시킨다(Cohen 등, 2010). 한편 심뇌혈관계 질환이 우울증 발생에 전향적인 연관 성이 있다는 점, 그리고 대사증후군이 심뇌혈관계 질환의 임상적 발현에 앞서 있는 중간적 상태의 특성을 지닌 다는 점을 고려할 때 우울증이 대사증후군의 발생과도 연관이 있을 수 있다는 추론도 배 재 할 수 없다. 우울증을 동반한 사람들은 상대적으로 부정적 건강 행동 예를 들면 흡연, 비건강식 섭취, 수동적 생활습관, 그리고 치료 에 대한 낮은 순응 등을 흔히 보인다(Blumenthal 등, 1982). 이런 행동들이 대사증후군을 야기시키고 결과적으로 심혈관계 질환을 발생시킬 가능성이 있다. 본 연구 결과는 대사증후군 5 가지 요소 중 혈당이 우울과 상관관계가 있음을 보여준다. 대사증후군환자 관리 시 신체적 관리 뿐만 아니라 정신건강 관한 중재를 시행 할 필요성 을 강조하고 싶다. 이를 통해 스트레스 및 우울에 관한 중재는 대사 증후군환자의 치료결과에도 영향을 끼칠 것으로 사료된다.

본 연구의 제한점으로는 단면연구이므로 대사증후군 요소와 우 울과 스트레스의 인과관계를 밝히는 데는 한계가 있다는 점이다. 이러한 제한점에도 불구하고 본 연구는 대사증후군 및 우울과 깊은 관련성이 있는 심뇌혈관계 질환을 통제하여 분석하여 대사증후군 5 가지 요소 중 혈당이 우울과 관련성이 있다는 점과 대한민국 전국 단위의 건강 영양조사인 국민건강영양조사 원시자료를 이용하여 우리나라 성인의 대사증후군 5가지 요소와 우울과 스트레스 관계 를 살펴보았다는데 큰 의의가 있다고 하겠다.

\section{Acknowledgements: None \\ Funding: None \\ Conflict of interest: None}




\section{References}

1. Alexopoulus GS, Meyers BS, Youn Rc, et al. "Vascular depression" hypothesis. Arch Gen Psychiatry. 1997, 54:915-922.

2. Blumenthal JA, Williams RS, Wallace AG, et al. Physiological and psychological variables predict compliance to prescribed exercise therapy in patients recovering from myocardial infarction. Psychosom Med. 1982, 44:519-527.

3. Cho HJ, Choi YJ, Kim YJ. The clustered metabolic risk factors among patient with ischemic stroke-A preliminary study. Korean J Stroke. 2003, 5: Abstract.

4. Cohen BE, Panguluri P, Na B, et al. Psychological risk factors and the metabolic syndrome in patients with coronary heart disease: Findings from the Heart and Soul Study. Psychiatry Res. 2010, 175:133-137.

5. Hadaegh F, Mohebi R, Cheraghi L, et al. Do different metabolic syndrome definitions predict cerebrovascualr events and coronary heart disease independent of their components?: 9 years follow- up of the tehran lipid and glucose study. Stroke; a journal of cerebral circulation. 2012, 43:1669-1671.

6. Husseini, Nada, Larry B, Eric D, Zhao, Xin, Wenqin Olson, et al. Depression and Antidepressant Use After Stroke and Transient Ischemic Attack. Stroke. 2012, 43:1609-1616.

7. Horwich TB, Fonarow GC. Glucose,obesity, metabolic syndrome, and diabetes relevance to incidence of heart failure. Journal of the American college of cardiology. 2010, 55:283-293.

8. Heuser I. Depression, endocrinologically a syndrome of premature aging? Maturitas. 2002, 1:19-23.

9. Korean society for the study of obesity. Clinical obesity. 3th ed. 2008, Seoul. 249-272.

10. Ninomiya JK, L'Italien G, Criqui MH, et al. Association of the metabolic syndrome with history of myocardial infarction and stroke in the Third National Health and Nutrition Examination Survey. Circulation. 2004, 109:42-46.

11. Olijhoek JK, van der Graaf Y, Banga JD, et al. the SMART Study Group. The metabolic syndrome is associated with advanced vascular damage in patients with coronary heart disease, stroke, peripheral arterial disease or abdominal aortic aneurysm. Eur Heart J. 2004, 25:342-348.

12. Schmidt C, Bergstrom GM. The metabolic syndrome predicts cardiovascular events: results of a 13-year follow-up in initially healthy 58-year-old men. Metabolic syndrome and related disorers. 2012, 10:394-399.

13. Song YG, Dan Liuc, Johnny. S.H. Kwan, et al. Depression in college: Depressive symptoms and personality factors in Beijing and Hong Kong college freshmen. Comprehensive Psychiatry. 2008, 49: 496-502.

14. Warren DT, David CS, James Rm, et al. Whitematter hyperintensity progression and late-life depression outcomes. Arch Gen Psychiatry. 2003, 60:1090-1096.

15. 권이승, 이상혁. 우리나라 성인의 대사증후군 관련인자 환경요인. 한국 생활환경학회지. 2012, 12:676-688.

16. 권현민, 김범준, 이성훈, 최성호, 오병희, 윤병우. 건강한 사람의 뇌경색 독립적인 위험인자 대사증후군. 대한되졸중학회. 2006, 37:466-470.

17. 김용재. 대사증후군과 뇌졸중. 대한신경과학회. 2005, 23:16-23.

18. 박은옥, 김문두, 손영주 등. 제주지역 성인의 우울 유병률과 관련 요인. 지역사회간호학회지. 2009, 20:277-284.

19. 윤대현, 박진호, 조수철, 박민정, 김선신, 최승호 등. 한국여성에서 우울 증상과 대사증후군의 관련성. 대한비만학회지. 2005, 14:213-219.

20. 최 령, 문현주, 황병덕. 만성질환이 노인들의 스트레스인지, 우울증상 경험 및 자살생각에 미치는 영향. 보건의료산업학회지. 2010, 4:73-84. 